\title{
Manipulating the sulfur amino acid content of the early diet and its implications for long-term health
}

\author{
William D. Rees \\ The Rowett Research Institute, Greenburn Road, Bucksburn, Aberdeen AB21 9SB, UK
}

\begin{abstract}
Epidemiological studies of human populations show that poor growth in utero predisposes an individual to the later development of type 2 (non-insulin-dependent) diabetes mellitus and hypertension in adulthood. This phenomenon is not confined to man; feeding pregnant rats diets moderately deficient in protein has a similar effect, programming the adult blood pressure and glucose metabolism of the offspring. A restriction in the amino acid supply was thought to cause poor fetal growth. However, recent experiments have shown that this is not the case and instead have implicated the metabolism of the S-containing amino acids. Many semi-synthetic experimental diets contain an imbalance in S-containing amino acids, forcing the animal to synthesise a sizeable part of its cysteine requirement from methionine. Unfortunately, when the diet is low in protein, the oxidation of amino acids is reduced, perturbing methionine metabolism and increasing levels of homocysteine. It is this interaction between protein content and composition of the diet which influences neonatal viability and may also determine the long-term health of the offspring. An excess of homocysteine is known to affect levels of two of the main mediators of cellular methylation reactions, S-adenosyl methionine and methylene tetrahydrofolate. S-adenosyl methionine is the methyl donor for the methylation of newlysynthesised DNA, regulating chromatin assembly and gene expression. The balance between S-adenosyl methionine and the methylated derivatives of folic acid may be critical for the development of differentiating cells and the long-term regulation of gene expression.
\end{abstract}

Fetal programming: Metabolic syndrome: Hypertension: Homocysteine: DNA methylation

There is a growing body of evidence suggesting that the early diet influences the subsequent susceptibility to disease. All adult cells develop from precursor stem cells, so it is not surprising that the fetal and neonatal periods of life are particularly sensitive to inadequate nutrition. Small defects introduced at an early stage are likely to propagate through the subsequent lineages and affect whole tissues. As well as affecting the mature body size there is evidence in both man and experimental animals which links impaired fetal growth with lifelong effects on metabolism, blood pressure, bone function, the immune system and brain development (Godfrey \& Barker, 2000). The maternal diet is an important determinant of fetal growth and, therefore, a major factor influencing disease susceptibility in the offspring.

The fetus draws its nutrient supply from the maternal circulation, the composition of which depends on both the intake and metabolism of the mother. During the course of gestation maternal metabolism changes in order to meet the differing demands of the fetus and to support mammary development. The mother also provides a buffer against day-to-day variations in the diet, and in the event of a shortage can mobilise nutrients from her own tissues in an attempt to make up the deficit. These nutrients support the fertilised oocyte as this one precursor cell undergoes a complex process of growth, while at the same time an elaborate signalling system controls the development of the three-dimensional body structure (for example, see MorrissKay et al. 2001). Chemical gradients (Patten \& Placzek, 2000) and signals generated by cell-to-cell contacts (McNeil, 2000) commit individual undifferentiated stem cells into particular lineages. Initially, trophectoderm cells produce the placenta, while the inner cell mass forms the rest of the body. Once the neural tube has formed the major axes are defined, enabling the process of limb and visceral development to begin.

In vitro studies have been essential in elucidating the mechanisms that control the process of differentiation. Embryonal carcinoma cells were used initially (Strickland 


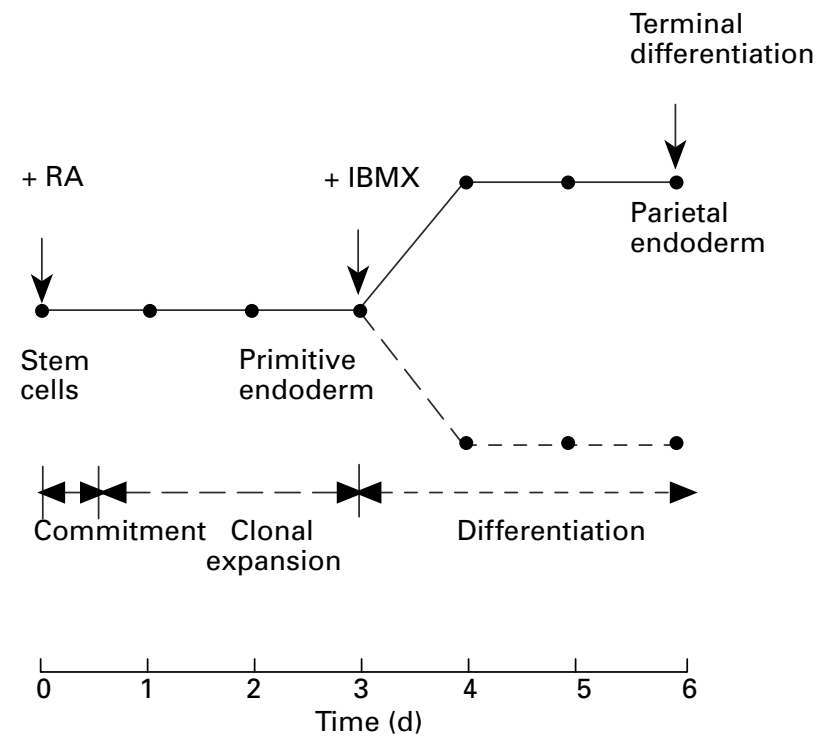

Fig. 1. The time-course for the differentiation of F9 embryonal carcinoma cells. Treatment of the cells with retinoic acid (RA) and an inhibitor of phosphodiesterase (IBMX) initiates the differentiation process. (๑), Time points indicating the progress (d).

\& Mahadavi, 1978; Strickland et al. 1980), although they are now being replaced by true embryonic stem cells (Burdon et al. 1999). Fig. 1 shows a typical time line for the differentiation of a cell into one of two lineages. In this case stimulation of the cells with retinoic acid, the active derivative of vitamin $\mathrm{A}$, initiates the differentiation process by binding to specific nuclear receptors present in the stem cells (Mark et al. 1999). The liganded receptors trigger the expression of the genes that commit the stem cells to a particular lineage (Maden, 2000; Plassat et al. 2000). Once committed the cells continue to divide in a period of clonal expansion before reacting to a second series of signals that determine the final phenotype. In the case of F9 cells these secondary signals involve membrane receptors that activate kinase-signalling cascades. Changes in intracellular cAMP, caused by treating the F9 cells with the phosphodiesterase inhibitor IBMX, regulate the terminal differentiation of the cells into visceral or parietal endoderm. During this period of cell differentiation there are major changes in the nucleus of the cell. Genes necessary for the differentiated cell are activated, while those no longer required are silenced (Patterton \& Wolffe, 1996). In the whole animal this basic process is repeated during several phases of differentiation, leading to the eventual terminal differentiation of cells.

\section{Diet composition and fetal growth}

Useful as they are for the determination of mechanisms of differentiation, in vitro studies are unable to replicate the complex nutrient interactions that occur in the whole animal. The pregnant rat fed deficient rations is one of the most widely used and extensively characterised animal models for the fetal origins of disease. Fetal growth restriction programmes a number of different functions, including growth, glucose tolerance and blood pressure, in the adults. In the simplest model the experimental animals are fed a predetermined proportion of the total amount of stock diet consumed by controls with ad libitum access (Bertin et al. 1999). With this global deprivation it is difficult to ascribe the effects to any single nutrient. However, a number of studies of single nutrient deficiencies have shown that reducing the protein content of the diet is all that is required to programme the offspring (for review, see Gardner et al. 1998; Ozanne \& Hales, 1999). The rat normally requires a diet containing approximately $180 \mathrm{~g}$ crude protein $(\mathrm{N} \times 6 \cdot 25) / \mathrm{kg}$ during gestation. Feeding an isoenergetic diet containing $90 \mathrm{~g}$ crude protein $/ \mathrm{kg}$ is sufficient to set the animals on a different growth trajectory, resulting in adult body weights that are 10-20\% lower than those of the controls. More importantly, the offspring of the protein-restricted dams go on to show elevated adult blood pressure (Langley \& Jackson, 1994) and changes in glucose tolerance. These latter effects result from functional differences in the liver, islet cells and adipose tissue (Snoeck et al. 1990; Desai et al. 1997; Shepherd et al. 1997). As a result the animals exhibit a type of insulin resistance that has many of the characteristics of human maturity-onset (type 2) diabetes.

Unfortunately, the results of intervention trials in human subjects suggest that protein supplementation does not improve maternal or fetal growth (Kramer, 2000). Thus, there has been some controversy as to whether the proteindeficient pregnant rat is an appropriate rodent model of the epidemiological observations in man. Further confusion arises because of a number of apparently conflicting results. Subtle differences in the amino acid composition of the diets impact on the development of hypertension (Langley-Evans, 2000). Also, the critical window seems to be somewhat unclear and unconnected with growth retardation. The lowprotein diet needs to be fed for just the first $4 \mathrm{~d}$ after conception to increase the blood pressure of the offspring (Kwong et al. 2000). It has been suggested that a perturbation of pre-implantation growth is sufficient to alter the allocation of cells in the blastocyst. By changing the number of cells in the inner cell mass relative to those in the trophectoderm the entire growth trajectory of the fetus may be disturbed. However, other studies suggest the proteindeficient diet causes little or no effect on the overall growth of the fetus up to day 19 of gestation; indeed, the pups of the dams fed the low-protein diet are somewhat larger than the controls (Rees et al. 1999). It is only in the very last stages of gestation, between days 19 and 22, that there is a 15-20\% reduction in fetal growth. Other experiments suggest that growth restriction caused by global feed restriction from day 15 onwards can also have a long-term effect on glucose tolerance, affecting critical organs such as the endocrine pancreas (Garofano et al. 1997). All these observations suggest that the programming of fetal growth and development is not the result of a simple growth restriction, but is the product of more fundamental metabolic changes in mother or fetus. 


\section{Metabolic changes associated with protein deficiency in the rat}

The link between maternal protein intake and the subsequent development of hypertension and metabolic disease in the offspring implicates amino acid metabolism in the mechanism. The fetus is largely autonomous for growth factors, it simply depends on the maternal circulation for its nutrient supply (Alsat et al. 1995). Generally, circulating amino acid levels fall during the first two thirds of gestation and then rise again at the end, presumably in order to support mammary development. With the notable exception of threonine, the concentrations of circulating amino acids in both mother and fetus are very similar in the high- and low-protein groups. This finding is consistent with the mobilisation of maternal tissues to compensate for the reduced intake. However, threonine is unusual, because by day 19 of gestation threonine concentrations in both the maternal circulation and in the fetuses of dams fed the lowprotein diet are 50-60\% lower than those in dams fed the high-protein diet (Rees et al. 1999). This decrease is not the result of a deficiency, since supplementation of the diet with additional threonine does not improve growth (Rees et al. 2000). Instead, there is an increase in threonine oxidation that is characteristic of an excess of methionine in the diet (Girard-Globa et al. 1972).

The experimental diets used in the vast majority of experiments use casein as the protein source, because it is a readily available, pure and highly-digestible protein. Although casein is well balanced with respect to its amino acid composition, it is deficient in cysteine (Table 1) and does not meet the animals' requirements (Reves, 1997). For most experiments this deficiency is simply rectified by supplementing the diet with additional crystalline methionine, which the maternal liver then converts into cysteine by trans-sulfuration (Fig. 2). First, methionine is converted to the adenylated derivative, S-adenosyl methionine, which sheds the S-methyl group to a suitable methyl acceptor. Hydrolysis of S-adenosyl homocysteine then yields homocysteine. Cystathionine produced from homocysteine by its reaction with serine is then hydrolysed to form cysteine. Animals fed casein-based semi-synthetic diets must produce at least $60 \%$ of their cysteine requirement by this route. The final enzyme in the pathway, serine-threonine dehydratase (cystathionine $\gamma$-lyase; SDH), also hydrolyses serine and threonine. An induction of SDH to oxidise excess homocysteine also increases the oxidation of threonine, causing circulating concentrations to fall (Girard-Globa et al. 1972; Rees et al. 2000).

Table 1. Sulfur amino acid content of semi-synthetic diets

\begin{tabular}{|c|c|c|c|c|}
\hline & \multicolumn{2}{|r|}{ Cysteine } & \multicolumn{2}{|c|}{ Methionine } \\
\hline & $\mathrm{mg} / \mathrm{g}$ & $\begin{array}{l}\% \text { estimated } \\
\text { requirement }\end{array}$ & $\mathrm{mg} / \mathrm{g}$ & $\begin{array}{l}\% \text { estimated } \\
\text { requirement }\end{array}$ \\
\hline $\begin{array}{l}\text { Estimated minimum } \\
\text { requirement (AIN-93G)* }\end{array}$ & $\begin{array}{l}3 \cdot 7 \\
1 \cdot 2\end{array}$ & & $4 \cdot 6$ & \\
\hline $\begin{array}{r}\text { Casein diet (g casein } / \mathrm{kg}) \\
180 \\
90\end{array}$ & 0.8 & $\begin{array}{l}33 \\
21\end{array}$ & $\begin{array}{l}9 \cdot 4 \\
6 \cdot 7\end{array}$ & $\begin{array}{l}204 \\
145\end{array}$ \\
\hline
\end{tabular}

${ }^{*}$ Reves (1997).
Homocysteine is well recognised as a highly-toxic nonprotein amino acid. With sizeable amounts of homocysteine being produced as a result of the conversion of methionine to cysteine, there is the danger of homocysteine accumulating. The removal of homocysteine depends on cystathionine synthase and SDH (Fig. 3). Homocysteine is first combined with serine to form cystathionine, which is then cleaved to form cysteine and 2-oxobutyrate. Although the activity of cystathionine synthase remains constant

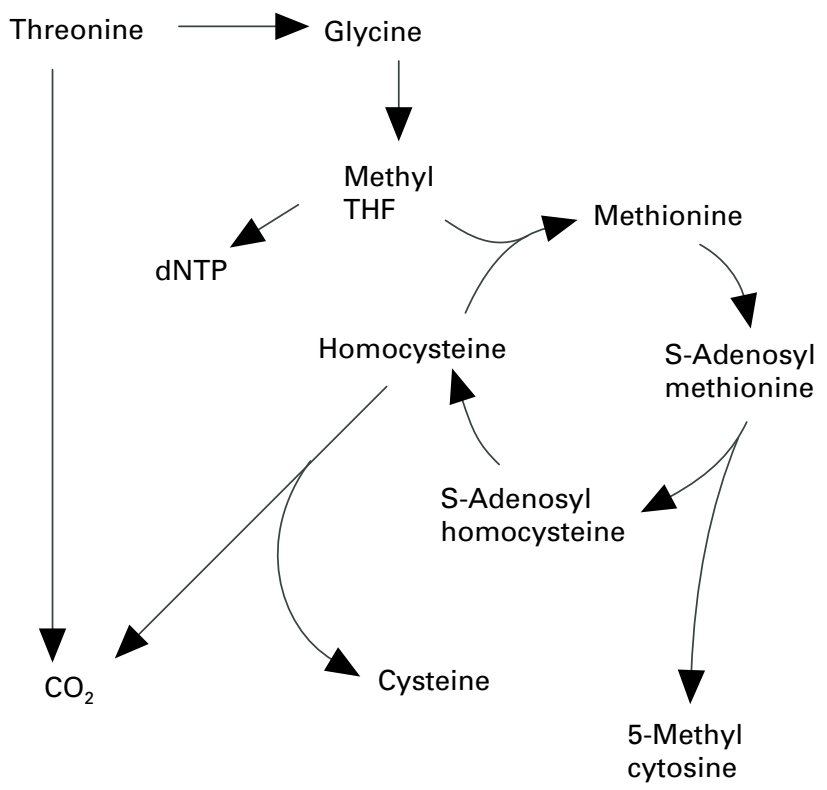

Fig. 2. Pathways for the metabolism of threonine, methionine and cysteine. Methyl THF, methylene tetrahydrofolate; dNTP, deoxy nucleotide triphosphates.

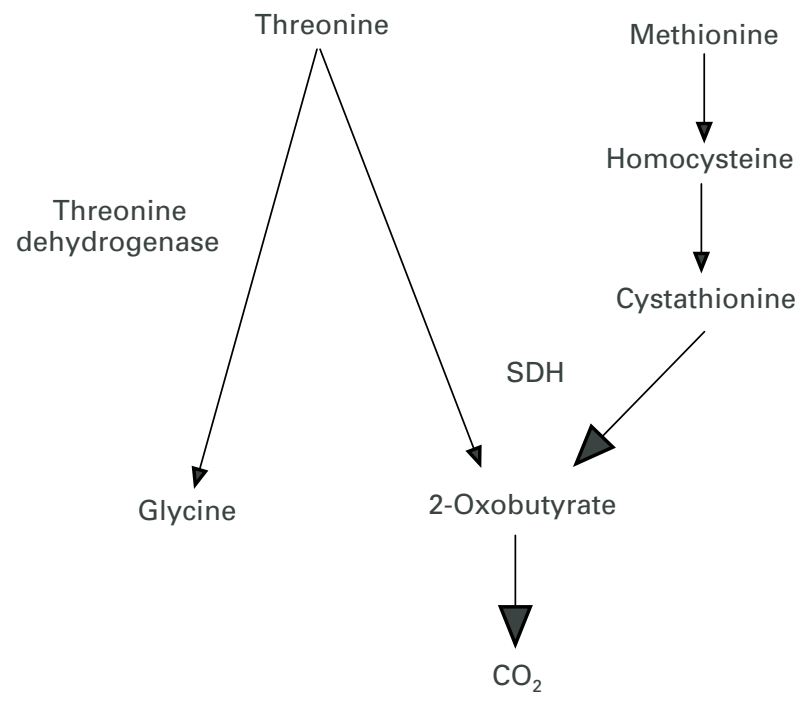

Fig. 3. Pathways for the oxidation of threonine and their interactions with methionine and homocysteine metabolism. SDH, cystathionine $\gamma$-lyase. 
during the course of pregnancy, the activity of SDH changes. In animals fed a normal diet the activity of SDH remains high during the first $4 \mathrm{~d}$ of pregnancy, but by day 11 has fallen to about $25 \%$ of the starting activity (Rees \& Hay 2001). This decline probably corresponds to a general decrease in amino acid oxidation in the middle of gestation that spares amino acids to support the increasing demands for fetal growth. In the animals fed the protein-deficient diet the need to conserve amino acids occurs earlier, so the enzyme activity, which is already lower than that in the nonpregnant animals, falls rapidly to $25 \%$ of the starting activity by day 4 of gestation (Rees \& Hay, 2001). Unfortunately, the animals fed the casein-based experimental diets still need to oxidise similar amounts of homocysteine to meet their cysteine requirement. Thus, the fall in SDH activity may explain why the circulating levels of homocysteine in dams fed low-protein diets are double those of the dams fed the high-protein diet on day 4 of gestation (WD Rees, SM Hay, C Antipatis, J McConnell, L Pietrie and DS Brown, unpublished results). As homocysteine is not normally released from the cells, the intracellular levels may be even higher.

The decrease in SDH activity that occurs in protein deficiency is probably caused by endocrine changes. One group of hormones known to change in response to protein intake is the glucocorticoids. These hormones also regulate the expression of the SDH gene, since the promoter contains a glucocorticoid response element (Su \& Pitot, 1992). Indeed, even relatively mild stresses such as laparotomy are able to induce the expression of the enzyme (Ogawa et al. 1995). Once changes in SDH activity have been initiated, it is not clear whether they can be restored if the animal is returned to a high-protein diet. If protein deficiency or another stress that elevates glucocorticoids can suppress SDH activity early in pregnancy, the reduced metabolic activity may persist throughout the remainder of gestation.

\section{Homocysteine and the derivatives of folic acid}

The other pathway for homocysteine metabolism involves methionine synthase, which utilises methylene tetrahydrofolate to re-synthesise methionine (Fig. 4). Folic acid is well recognised as an essential nutrient during pregnancy, and a deficiency leads to an increase in the incidence of neural tube defects (van der Put et al. 2001). If substantial quantities of methylene tetrahydrofolate are used for the remethylation of homocysteine, then the pool of this active derivative of folic acid becomes depleted (James et al. 1997). An excess of methionine or homocysteine is therefore in some ways similar to a dietary folate deficiency. A number of different amino acids, particularly glycine, provide the methyl groups required for the synthesis of methylene tetrahydrofolate and determine the availability of methylated folates. This replenishment of the methylated folate pool may explain the reversal of the hypertensive effect observed when the casein-based diet is supplemented with glycine (Dunn et al. 2001). The re-methylation of homocysteine to reform methionine potentially sets up a cycle that transfers methyl groups from methylene tetrahydrofolate into S-adenosyl methionine (Fig. 4). Thus, the balance of these two essential intermediates in methyl

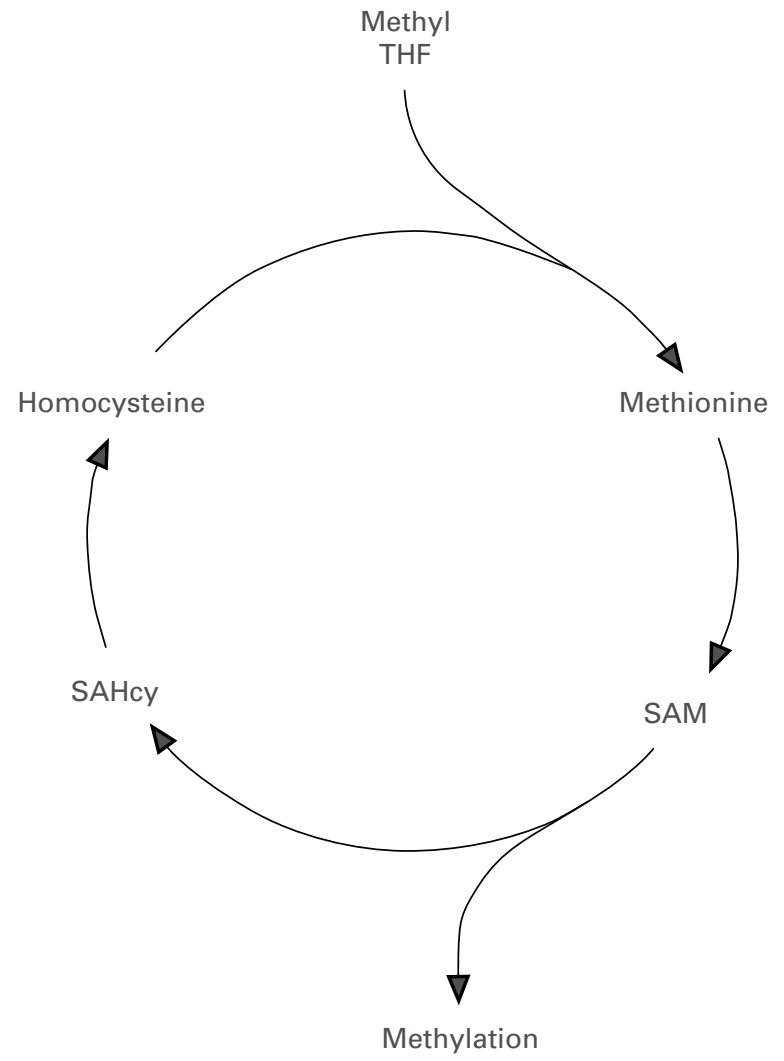

Fig. 4. A pathway for the transfer of methyl groups. Methyl groups from methylene tetrahydrofolate (methyl THF) are used for the remethylation of homocysteine. The methionine cycle transfers these methyl groups to methylation reactions which utilise S-adenosyl methionine (SAM) as cofactor. These reactions include the methylation of DNA. SAHcy, S-adenosyl homocysteine.

transfer reactions is determined by the amount of homocysteine present in the system. The functional methylene tetrahydrofolate deficiency generated by excess homocysteine may affect all the essential metabolic pathways that require this cofactor. These pathways include nucleotide and choline synthesis. The consequences of a deficiency in the products of these pathways remain to be seen. For example, the semi-synthetic experimental diets are almost devoid of preformed nucleotides, so the entire supply must be synthesised de novo. In adults depletion of the folate pool leads to a reduction in the deoxy nucleotide triphosphate pools and the rate of DNA synthesis (Jackson et al. 1997). The effect of stalling DNA synthesis during the differentiation of cells is unknown, but may, for example, disrupt chromatin formation.

\section{Methionine homocysteine and DNA methylation}

DNA is one of the critical molecules that accept methyl groups from S-adenosyl methionine. Changes in methylation are an essential step in cell differentiation and part of normal fetal development (Martin et al. 1999; Leonhardt \& Cardoso, 2000; Rountree et al. 2001). Analysis of the DNA from the fetuses of dams fed the methionine-imbalanced 
low-protein diets showed that in some tissues, particularly the fetal liver, the methylation of DNA was increased (Rees et al. 2000). This process may be an important mechanism linking the metabolic changes to the development of fetal cells.

The functional consequences of DNA methylation are wide ranging. About $5 \%$ of the cytosine residues in mammalian DNA are methylated at the 5 position of the cytosine ring. However, this modification is not randomly distributed, but occurs in a highly organised manner. First, it depends on the neighbouring base and normally occurs at dinucleotides with the sequence of cytosine residue $5^{\prime}$ to guanosine residue $(\mathrm{CpG})$. If the structure of DNA were random, then there is an equal probability that a cytosine residue would be followed by any of the four bases. However, the sequence $\mathrm{CpG}$ is found at only about one-third of expected frequency in mammalian genomes. In most parts of the genome about $70 \%$ of cytosine residues followed by a guanosine residue are methylated. These simple repetitive DNA sequences, which are regularly dispersed throughout the genome, are the target for specific methyl CpG-binding proteins that anchor the DNA to the nuclear matrix. Since these regions map to the boundaries of active chromatin and intronic regions of genes, they have the capability to control access for transcription and regulate gene expression (Epplen et al. 1996).

Second, there are groups of $\mathrm{CpG}$ residues where only about $30 \%$ of the cytosine residues are methylated (Gardiner-Garden \& Fromer, 1987). These regions, known as $\mathrm{CpG}$ islands, are found either within or adjacent to about half the sequences that encode genes. Methylation of cytosine residues in the $\mathrm{CpG}$ islands has both positive and negative effects on the expression of the neighbouring genes. Numerous studies suggest that hypermethylation of $\mathrm{CpG}$ islands within the promoter correlates with decreased expression of the gene. On the other hand, hypermethylation of $\mathrm{CpG}$ sequences downstream of the promoter correlates with increased expression. Once established, the $\mathrm{CpG}$ methylation status of a particular gene is normally preserved during cell division. Changes in DNA methylation are particularly important during neoplastic progression and correlate with the activity of the promoter (Wong et al. 1999). As with the matrix attachment sites, the $\mathrm{CpG}$ islands are also believed to be important in regulating chromatin structure and therefore the accessibility of DNA for transcription.

DNA methylation can have very widespread effects on gene expression and the most dramatic of these effects is the silencing of an entire X chromosome (Avner \& Heard, 2001). Methylation also silences large parts of other chromosomes, so that only the paternally- or maternallyinherited gene is expressed. One of the best characterised of these systems is the insulin-like growth factor 2 (IGF2) and IGF2/mannose 6-phosphate receptor genes which are expressed from the maternally and paternally-inherited alleles respectively (for a recent review, see Wolffe, 2000). Other imprinted genes include a number of essential growth factors and regulators. The importance of this system in regulating fetal growth is illustrated by studies of mice with targeted mutations of the IGF2 gene. Normal mice have only one active copy of the IGF2 gene. Deleting the methylation-sensitive region activates the silenced copy of the IGF2 gene, doubling IGF2 production and causing fetal overgrowth. Deleting the maternally-inherited IGF2/ mannose-6-phosphate receptor, which controls IGF2 removal, also causes fetal overgrowth (Wang et al. 1994). However, it is not necessary to delete whole sections of DNA to cause changes in growth, much milder insults can also alter methylation and growth. Exceptionally-large offspring are a common result of embryo transfer in ruminant species. There is now evidence that this large-offspring syndrome is coupled to changes in the expression of IGF2 receptor (Khosla et al. 2001; Young et al. 2001). Manipulating the diet can also regulate epigenetic gene expression. Methyl-supplemented diets containing methionine, betaine, folic acid and vitamin $\mathrm{B}_{12}$ have been shown to alter patterns of epigenetic gene expression in the agouti mouse (Wolff et al. 1998). It is not yet clear whether the imprinted genes are major targets with regard to the development of hypertension and metabolic disease following growth retardation in utero. The perturbation of S-adenosyl methionine levels may also interfere with the changes in methylation that affect both alleles during normal differentiation.

The methylation reactions involve two separate DNA methyltransferase systems. Interestingly, as well as S-adenosyl methionine, the methyltransferases also require $\mathrm{Zn}$ as a cofactor (Bestor, 1992). Zn is essential during pregnancy, and deficiencies are teratogenic. The first system involves a maintenance methylase (coded by the DNA methyltransferase 1 gene) which copies the pattern of methylation from the template strand onto the newlysynthesised DNA and preserves the existing pattern during each round of cell replication. There is, therefore, a clear mechanism for a heritable programming of gene function through changes in DNA methylation. This pattern is preserved during the differentiation of cells as the maintenance methylases copy the pattern to the newlysynthesised strand.

In the second class of reaction de novo methylases (coded for by the DNA methyltransferase 2 and 3 genes) introduce new patterns during differentiation of tissues. These enzymes are essential for normal fetal development, and mutations are lethal for the developing fetus (Okano et al. 1999). It is possible that high levels of intracellular S-adenosyl methionine may cause a substrate-driven increase in methylation affecting the establishment of new methylation patterns. The product of the transmethylation reaction, S-adenosyl homocysteine, can also affect the outcome, since it acts as a product inhibitor of the enzyme (O'Gara et al. 1996). If it is not removed quickly enough there is the possibility that its accumulation may inhibit the DNA methyltransferase activity during key methylation reactions.

The methyl transferases are only part of a complex system that regulates chromatin formation. A complex of proteins, which includes several methyl CpG-binding proteins and histone acetyl transferase, binds to newlysynthesised DNA and regulates its packaging into chromatin (Fig. 5). This complex is important in deciding whether the DNA is packaged into open or condensed chromatin and determines subsequent gene expression. It is important not 


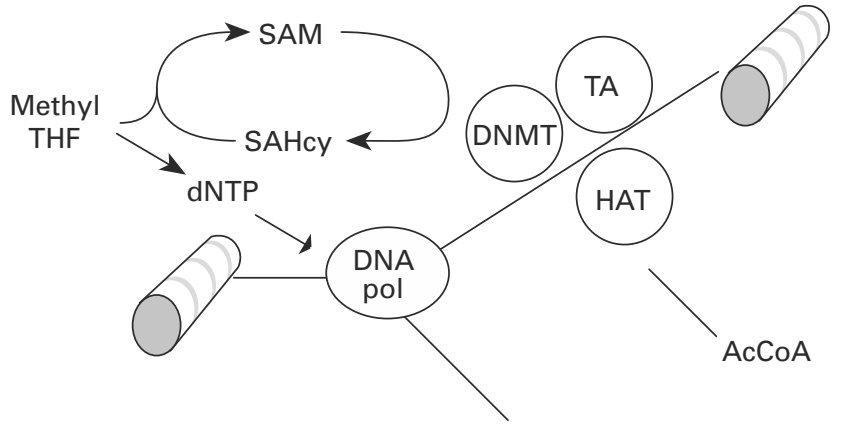

Fig. 5. Interactions between metabolism and chromatin formation. The DNA molecule is wound around a histone former. As the cell replicates it is uncoiled and replicated by the DNA polymerase complex (DNA pol). A complex of DNA methyltransferase (DNMT), transcriptional activators or CpG-binding proteins (TA) and histone acetyl transferase (HAT) bind to the newly-synthesised strand. This complex utilises S-adenosyl methionine (SAM) and acetyl-CoA (Ac$\mathrm{CoA}$ ) to modify the DNA and histones whilst forming the new chromatin structure. Methyl THF, methylene tetrahydrofolate; SAHcy, Sadenosyl homocysteine; dNTP, deoxy nucleotide triphosphates.

to oversimplify the complex interactions that occur when chromatin is remodelled. The process of DNA methylation may depend on or generate an altered chromatin state that suppresses gene expression (Fuks et al. 2000). Histone acetylation is another essential part of the remodelling process and depends on acetyl-CoA as its substrate. This factor raises interesting questions on the role of acetate metabolism in determining chromatin structure. The metabolic interactions which control gene expression through long-range chromatin interactions are an exciting new type of gene-nutrient interaction, and one which is just beginning to be explored.

\section{Future prospects}

There is clear evidence that protein deficiency changes the flux through the $\mathrm{S}$ amino acid cycle. It becomes of increasing importance to know whether this mechanism is the only one that programmes adult disease or whether other factors such as restricted cellular growth also play a role. One of the principal criticisms of the protein-deficiency model in the rat is that protein deficiency itself is not a recognised problem in man. The recent animal data from the rodent models is providing increasing evidence for complex interactions between dietary protein content, quality and micronutrient composition. All these factors can be involved in the nutritional regulation of chromatin structure and the long-term programming of gene expression. These data suggest that the methylation reactions and the micronutrients involved in them may be far more important than the bulk amino acid supply. Indeed, it may be possible to produce a small but symmetrical growth retardation without any impact on long-term health. It is only when the metabolism of the $\mathrm{S}$ amino acids is disturbed that long-term changes are programmed in cell function.
Whilst all these studies have concentrated on the role of the $\mathrm{S}$ amino acids during pregnancy, it is important to realise that similar processes continue in a number of cell types during adult life. For example, the immune system, the gut and endothelial cells are continually renewing themselves from stem cells. Homocysteine is a recognised risk factor for diseases associated with these cells, suggesting that these metabolic perturbations may have much more widespread implications for dietary manipulation.

\section{Acknowledgements}

This work was supported by the Scottish Office Rural Affairs Department.

\section{References}

Alsat E, Marcotty C, Gabriel R, Igout A, Frankenne F, Hennen G \& Evian-Brion D (1995) Molecular approach to intrauterine growth retardation: an overview of recent data. Reproduction, Fertility and Development 7, 1457-1464.

Avner P \& Heard E (2001) X-chromosome inactivation: counting, choice and initiation. Nature Reviews in Genetics 2, 59-67.

Bertin E, Gangnerau MN, Bailbe D \& Portha B (1999) Glucose metabolism and beta-cell mass in adult offspring of rats protein and/or energy restricted during the last week of pregnancy. American Journal of Physiology 277, E11-E17.

Bestor TH (1992) Activation of mammalian DNA methyltransferase by cleavage of a $\mathrm{Zn}$ binding regulatory domain. $E M B O$ Journal 11, 2611-2617.

Burdon T, Chambers I, Stracey C, Niwa H \& Smith A (1999) Signaling mechanisms regulating self-renewal and differentiation of pluripotent embryonic stem cells. Cells Tissues Organs 165, 131-143.

Desai M, Byrne CD, Meeran K, Martenz ND, Bloom SR \& Hales CN (1997) Regulation of hepatic enzymes and insulin levels in offspring of rat dams fed a reduced-protein diet. American Journal of Physiology 273, G899-G904.

Dunn RI, Marchand MC, Langley-Evans SC \& Jackson AA (2001) Glycine repletion prevents the development of hypertension in rats exposed to maternal low protein diets in utero. Pediatric Research 50, Suppl., 26A.

Epplen JT, Kyas A \& Maueler W (1996) Genomic simple repetitive DNAs are targets for differential binding of nuclear proteins. FEBS Letters 389, 92-95.

Fuks F, Burgers WS, Brehm A, Hughes-Davies L \& Kouzarides T (2000) DNA methyltransferase associates with histone deacetylase activity. Nature Genetics 1, 88-91.

Gardiner-Garden M \& Fromer M (1987) CpG islands in vertebrate genomes. Journal of Molecular Biology 196, 261-282.

Gardner DS, Jackson AA \& Langley-Evans SC (1998) The effect of prenatal diet and glucocorticoids on growth and systolic blood pressure in the rat. Proceedings of the Nutrition Society $\mathbf{5 7}$, $235-240$

Garofano A, Czernichow P \& Breant B (1997) In utero undernutrition impairs rat beta-cell development. Diabetologia $\mathbf{4 0}$, 1231-1234.

Girard-Globa A, Robin P \& Forestier M (1972) Long-term adaptation of weanling rats to high dietary levels of methionine and serine. Journal of Nutrition 102, 209-218.

Godfrey KM \& Barker DJ (2000) Fetal nutrition and adult disease. American Journal of Clinical Nutrition 71, Suppl., $1344 \mathrm{~S}-1352 \mathrm{~S}$.

Jackson CD, Weis C, Miller BJ \& James SJ (1997) Dietary nucleotides: effects on cell proliferation following partial 
hepatectomy in rats fed NIH-31, AIN-76A, or folate/methyldeficient diets. Journal of Nutrition 127, 834S-837S

James SJ, Miller BJ, Basnakian AG, Pogribny IP, Pogribna M \& Muskhelishvili L (1997) Apoptosis and proliferation under conditions of deoxynucleotide pool imbalance in liver of folate/methyl deficient rats. Carcinogenesis 18, 287-293.

Khosla S, Dean W, Brown D, Reik W \& Feil R (2001) Culture of preimplantation mouse embryos affects fetal development and the expression of imprinted genes. Biology of Reproduction 64, 918-926.

Kramer MS (2000) Isocaloric balanced protein supplementation in pregnancy. Cochrane Database System Review 2000, 2, CD000118, available at http://www.update-software.com/ abstracts/ab000118.htm

Kwong WY, Wild AE, Roberts P, Willis AC \& Fleming TP (2000) Maternal undernutrition during the preimplantation period of rat development causes blastocyst abnormalities and programming of postnatal hypertension. Development 127, 4195-4202.

Langley SC \& Jackson AA (1994) Increased systolic blood pressure in adult rats induced by fetal exposure to maternal low protein diets. Clinical Science 86, 217-222.

Langley-Evans SC (2000) Critical differences between two low protein diet protocols in the programming of hypertension in the rat. International Journal of Food Science and Nutrition 51, $11-17$.

Leonhardt H \& Cardoso MC (2000) DNA methylation, nuclear structure, gene expression and cancer. Journal of Cellular Biochemistry 35, 78-83.

McNeill H (2000) Sticking together and sorting things out: adhesion as a force in development. Nature Reviews in Genetics 1, 100-108.

Maden M (2000) The role of retinoic acid in embryonic and postembryonic development. Proceedings of the Nutrition Society 59, 65-73.

Mark M, Ghyselinck NB, Wendling O, Dupe V, Mascrez B, Kastner P \& Chambon P (1999) A genetic dissection of the retinoid signalling pathway in the mouse. Proceedings of the Nutrition Society 58, 609-613.

Martin CC, Laforest L, Akimenko MA \& Ekker M (1999) A role for DNA methylation in gastrulation and somite patterning. Developmental Biology 206, 189-205.

Morriss-Kay GM, Iseki S \& Johnson D (2001) Genetic control of the cell proliferation-differentiation balance in the developing skull vault: roles of fibroblast growth factor receptor signalling pathways. Novartis Foundation Symposium 232, 102-116.

O'Gara M, Klimasauskas S, Roberts RJ \& Cheng X (1996) Enzymatic C5-cytosine methylation of DNA: mechanistic implications of new crystal structures for HhaL methyltransferase-DNA-AdoHcy complexes. Journal of Molecular Biology 261, 634-645.

Ogawa H, Kawamata S, Gomi T, Ansai Y \& Karaki Y (1995) Laparotomy causes a transient induction of rat liver serine dehydratase mRNA. Archives of Biochemistry and Biophysics 316, 844-850.

Okano M, Bell DW, Haber DA \& Li E (1999) DNA methyltransferases Dnmt3a and Dnmt3b are essential for de novo methylation and mammalian development. Cell 99, 247-257.

Ozanne SE \& Hales CN (1999) The long-term consequences of intrauterine protein malnutrition for glucose metabolism. Proceeding of the Nutrition Society 58, 615-619.

Patten I \& Placzek M (2000) The role of Sonic hedgehog in neural tube patterning. Cellular and Molecular Life Science 57, $1695-1708$.
Patterton D \& Wolffe AP (1996) Developmental roles for chromatin and chromosomal structure. Developmental Biology 173, 2-13.

Plassat J, Penna L, Chambon P \& Rochette-Egly C (2000) The conserved amphipatic alpha-helical core motif of RARgamma and RARalpha activating domains is indispensable for RAinduced differentiation of F9 cells. Journal of Cell Science 113, $2887-2895$.

Rees WD \& Hay SM (2001) Early changes in maternal sulphur amino acid metabolism caused by maternal protein deficiency. Pediatric Research 50, Suppl., 29A.

Rees WD, Hay SM, Brown DS, Antipatis C \& Palmer RM (2000) Maternal protein deficiency causes hypermethylation of DNA in the livers of rat fetuses. Journal of Nutrition 130, 1821-1826.

Rees WD, Hay SM, Buchan V, Antipatis C \& Palmer RM (1999) The effects of maternal protein restriction on the growth of the rat fetus and its amino acid supply. British Journal of Nutrition $\mathbf{8 1}$, 243-250.

Reves PG (1997) Components of the AIN-93 diets as improvements in the AIN 76A diet. Journal of Nutrition 127, Suppl., 838S-841S.

Rountree MR, Bachman KE, Herman JG \& Baylin SB (2001) DNA methylation, chromatin inheritance, and cancer. Oncogene 20, 3156-3165.

Shepherd PR, Crowther NJ, Desai M, Hales CN \& Ozanne SE (1997) Altered adipocyte properties in the offspring of protein malnourished rats. British Journal of Nutrition $\mathbf{7 8}$, $121-129$.

Snoeck A, Remacle C, Reusens B \& Hoet JJ (1990) Effect of a low protein diet during pregnancy on the fetal rat endocrine pancreas. Biology of the Neonate 57, 107-118.

Strickland S \& Mahadavi V (1978) The induction of differentiation in teratocarcinoma cells by retinoic acid. Cell 15, 393-403.

Strickland S, Smith KK \& Maroti KR (1980) Hormonal induction of differentiation in teratocarcinoma cells: Generation of parietal endoderm by retinoic acid and dibutyryl cAMP. Cell 21, 347-355.

Su Y \& Pitot HC (1992) Identification of regions in the rat serine dehydratase gene responsible for regulation by cyclic AMP alone and in the presence of glucocorticoids. Molecular and Cellular Endocrinology 90, 141-146.

van der Put NM, van Straaten HW, Trijbels FJ \& Blom HJ (2001) Folate, homocysteine and neural tube defects: an overview. Experimental Biology and Medicine 226, 243-270.

Wang ZQ, Fung MR, Barlow DP \& Wagner EF (1994) Regulation of embryonic growth and lysosomal targeting by the imprinted Igf2/Mpr gene. Nature 372, 464-467.

Wolff GL, Kodell RL, Moore SR \& Cooney CA (1998) Maternal epigenetics and methyl supplements affect agouti gene expression in Avy/a mice. FASEB Journal 12, 949-957.

Wolffe AP (2000) Transcriptional control: imprinting insulation. Current Biology 10, R463-R465.

Wong DJ, Foster SA, Galloway DA \& Reid BJ (1999) Progressive region-specific de novo methylation of the p16 $\mathrm{CpG}$ island in primary human mammary epithelial cell strains during escape from $\mathrm{M}(0)$ growth arrest. Molecular and Cellular Biology $\mathbf{1 9}$, $5642-5651$.

Young LE, Fernandes K, McEvoy TG, Butterwith SC, Gutierrez CG, Carolan C, Broadbent PJ, Robinson JJ, Wilmut I \& Sinclair KD (2001) Epigenetic change in IGF2R is associated with fetal overgrowth after sheep embryo culture. Nature Genetics 27, $153-154$ 